\title{
FLUXOS MIGRATÓRIOS E FRONTEIRAS: NECESSÁRIAS APROXIMAÇÕES ENTRE ARTE, POLÍTICA E DIREITO
}

\section{LA MIGRATION ET FRONTIÈRES: APPROXIMATIONS NÉCESSAIRES ENTRE L'ART, LA POLITIQUE ET LE DROIT}

\begin{abstract}
${ }^{1}$ Renato Duro Dias
\section{RESUMO}

A migração internacional é uma dimensão importante da globalização. Nas últimas décadas, a migração incorporou-se às mudanças no cenário mundial. Tendo em vista as fronteiras entre México e Estados Unidos e deste com Cuba, Norte da África e Sul da Europa, Israel e a Palestina, Francis Alÿs, artista visual, procura questionar os processos e fluxos migratórios, desvelando fronteiras físicas e simbólicas que fraturam os direitos humanos. A partir das obras, The Loop, Green Line, Bridge/Puente e Don't cross the bridge before you get to the river, este artigo problematiza as necessárias aproximações entre arte, política e direito.
\end{abstract}

Palavras-chave: Migração, Fronteira, Direitos humanos, Arte, Direito

\section{RESUMEN}

La migration internationale est une dimension importante de la globalisation. Au cours des dernières décennies, la migration incorporée à des changements dans le scénario global. Entre la frontière de Mexique et les États-Unis et cela avec Cuba, l'Afrique du Nord et Europe, Israël et la Palestine, Francis Alÿs, artiste, cherche interroger les processus et les flux migratoires, révélant les limites physiques et symboliques qui fracturent le droit de l'homme. Des œuvres, The Loop, Green Line, Bridge/Puente e Don't cross the bridge before you get to the river, cet article traite des approximations entre l'art, la politique et le droit.

Palabras-claves: Migration, Frontière, Droits de l'homme, Art, Droit

\footnotetext{
${ }^{1}$ Doutor em Educação pela Universidade Federal de Pelotas - UFPEL, Rio Grande do Sul (Brasil). Professor pela Universidade Federal do Rio Grande - FURG, Rio Grande do Sul (Brasil). E-mail: renatodurodias@ gmail.com
} 
Introdução

A migração internacional é uma dimensão importante da globalização. Nas últimas décadas, a migração se tornou cada vez mais incorporada às mudanças no cenário mundial, especialmente, nas estruturas econômicas e sociais. O crescente desenvolvimento, as disparidades demográficas e o fortalecimento de alguns regimes democráticos, em desfavor de outros autoritários, também, forneceram elementos para uma mobilidade transcontinental.

Por certo, a crise do emprego global, que se expandiu sobre boa parte do mundo em desenvolvimento, foi determinante para o acréscimo de pessoas que cruzaram fronteiras em busca de uma vida mais digna. É possível perceber um incremento deste movimento, sobretudo, se pensarmos nos aspectos geográficos, já que estas ondas migratórias afetaram (e afetam) múltiplas regiões do planeta.

Partindo de alguns marcos territoriais, especialmente, as fronteiras entre México e Estados Unidos e deste com Cuba, Norte da África e Sul da Europa, bem como os deslocamentos humanos entre Israel e a Palestina, Francis Alÿs (1959), artista visual belgo-mexicano, procura questionar os processos e fluxos migratórios, e, assim, desvelar estas fronteiras físicas e simbólicas que fraturam sobremaneira os direitos humanos destas populações em constante vulnerabilidade.

Tendo como referência as obras artísticas de Alÿs, The Loop (1997), Green Line (2005), Bridge/Puente (2006) e Don't cross the bridge before you get to the river (2008), este artigo problematiza as necessárias aproximações entre o campo das artes visuais, da política e do direito. Como diz Alÿs (2005) "Fazer algo de poético pode tornar-se político e, às vezes, fazendo algo de político tornar-se poético".

Importa salientar que com estas ações artísticas (BOURRIAUD, 2009; GUATARRI, 1996) Alÿs nos aponta mecanismos visuais para perceber os mundos que circundam a estética do movimento humano nos espaços, questionando o próprio conceito de fronteira. Entende-se que este processo de desterritorialização humana (CANCLINI, 2002), somado a proposta de arte politicamente engajada de Francis Alÿs, pode desvendar as tensões sociais existentes nas fronteiras e nos fluxos migratórios. 
Desta forma, o presente artigo divide-se em quatro (04) etapas. Nesta introdução, apresentam-se os objetivos, a metodologia e os referenciais teóricos. Logo a seguir, contextualizam-se contemporaneamente os fluxos migratórios, bem como se problematizam os conceitos de migração e fronteira. Numa terceira etapa, apresentamse as ações artísticas de Francis Alÿs, procurando discutir os pontos de contato com os temas desta investigação. Por fim, nas considerações finais, elencam-se pertinentes elementos das obras que destacam o papel político da arte visual.

Amparado no referencial iconográfico, utiliza-se o método de análise de imagens, buscando suas representações iconológicas (PANOFSKY, 1986, 2011). Para tal, utiliza-se de Alÿs (2015), Canclini (2012), Bourriaud (2009), Guatarri, (1996) e Koser (2007) e Dias (2014, 2015a, 2015b). Assim, este artigo pretende contribuir para o permanente diálogo entre arte, direito, política e cultura visual.

Fluxos migratórios e fronteiras

A migração constitui-se no movimento de pessoas em uma transposição de limites territoriais delimitados para o propósito de estabelecer uma nova residência, muitas vezes temporária. Geralmente, provocada por guerras ou necessidades econômicas, envolve o deslocamento de toda uma comunidade, mas também se refere à migração sazonal, mais frequentemente ligada às circunstâncias políticas.

\begin{abstract}
Numa perspectiva sociológica, as migrações são percebidas sob a ótica estruturalista como uma das conseqüências da crise neoliberal contemporânea. No contexto do sistema econômico atual, verifica-se o crescimento econômico sem o aumento da oferta de emprego. O desemprego passa a ser uma característica estrutural do neoliberalismo, e as pessoas, então, migram em busca, fundamentalmente, de trabalho. E isto se verifica tanto no plano interno como no internacional. Sobre a lógica do progresso econômico e do desenvolvimento social impera a lógica do lucro, onde todos os bens, objetos e valores são passíveis de negociação, como as pessoas e até os seus órgãos, a educação, a sexualidade e, inevitavelmente, os migrantes. (MARINUCCI; MILESI, 2007, p. 03)
\end{abstract}

O fenômeno da migração internacional é crescente. A segmentação dos mercados de trabalho dos países mais ricos e a criação de crescente demanda por trabalhadores migrantes avançaram muitíssimo nos dois últimos séculos. O Brasil, por exemplo, é um importante contexto destes fluxos migratórios.

Em relação à migração entre países, em 2010, o país recebeu 268,5 mil imigrantes internacionais, $86,7 \%$ a mais do que em 2000 (143,6 mil). Os 
principais países de origem dos imigrantes foram os Estados Unidos (51,9 mil) e Japão (41,4 mil). Verificou-se que o Brasil está recebendo de volta muitos brasileiros que estavam no exterior. Do total de imigrantes internacionais, 174,6 mil $(65,0 \%)$ eram brasileiros e estavam retornando; já em 2000, foram 87,9 mil imigrantes internacionais de retorno, $61,2 \%$ do total dos imigrantes. (IBGE ${ }^{1}, 2012$ )

Os meios de comunicação de massa, somados a crescente acessibilidade às redes de informação, também sensibilizaram pessoas, famílias e/ou comunidades a realizarem movimentos humanos ao redor do planeta. Outro elemento contribuiu para estes fluxos: as múltiplas modalidades de transporte. Estes modais (rodoviários, aéreos e marítimos) tornaram-se, nas duas últimas décadas, mais baratos e mais acessíveis, produzindo intensas redes de migração. De acordo com Koser (2007), "há uma indústria da migração".

No campo jurídico, os direitos e garantias fundamentais de migrantes se espraiaram em documentos internacionais e estão presentes na maioria das cartas constitucionais do mundo ocidentalizado, embora se questione a dificuldade de implementá-los.

Parte de las dificultades de protección, en el presente contexto del desarraigo, reside en los vacíos y lagunas de la normativa de protección existente. Nadie cuestiona, por ejemplo, la existencia de un derecho a emigrar, como corolario del derecho a la libertad de movimiento ${ }^{2}$. (CIDH, 2000, Voto de Antonio Augusto Cançado Trindade).

Este novo indivíduo migrante (KOSER, 2007) passou a gozar de direitos e prerrogativas capazes de permitir que certas pessoas cruzassem fronteiras e se situassem no estrangeiro com mais facilidade. Desde as referências ao direito cosmopolita de Kant, aos atuais marcos legais, expressos pelos mais importantes organismos internacionais, a migração cumpre importante papel na construção social dos direitos humanos.

\footnotetext{
A importância da Teoria de Direito Cosmopolita kantiana (1795), pouco mais de dois séculos após seu desenvolvimento, e sua correlação com o fenômeno da migração - que sempre esteve presente na história da humanidade, e que ora se apresenta como cerne de diversos conflitos na comunidade internacional -, é notável. Obviamente, não se faz necessária uma constituição única e que abrace toda humanidade perante as mesmas regras. A teoria se adapta ao discurso de que somos todos iguais enquanto raça humana, e que possuímos todos os mesmos valores. Todos prezam pela

${ }^{1}$ Fonte: www.ibge.gov.br

${ }^{2}$ Em tradução livre: "Parte das dificuldades de proteção, no presente contexto de desenraizamento, encontra-se nas lacunas e deficiências da proteção existente. Ninguém questiona, por exemplo, a existência de um direito de emigrar, como corolário do direito à liberdade de movimento.”
} 
obtenção da felicidade e da paz. São conceitos iguais para todas as pessoas, não importando onde habitam ou qual a sua proveniência. E a felicidade e a paz só podem ser obtidas através da concessão de direitos básicos e fundamentais, e a consequiente não violação dos mesmos. (KERBER, 2015, p. 34)

No entanto, todos estes fluxos migratórios, por vezes, acabam se tornando um importante elemento para a violação dos direitos humanos, como bem observa Araújo, ao mencionar a questão dos migrantes indocumentados:

\begin{abstract}
Os migrantes indocumentados não são apenas um grupo vulnerável. Sua vulnerabilidade não é uma fraqueza que se possa combater com a positivação de novos direitos e a codificação de novas normas. A sua história não pode ser desvinculada da história dos Estados nacionais. O Estado que abraça, que nacionaliza, que concede uma identidade para identificar e documentar, o Estado que inventou o passaporte é também o mesmo Estado que criou o imigrante ilegal, irregular e indocumentado. Mais que isso, trata-se de uma relação profunda, porque o Estado depende dessa exclusão para existir. (ARAÚJO, 2015, p. 34)
\end{abstract}

A vulnerabilidade social e o sentimento de não pertencimento têm gerado, especialmente nos migrantes, uma dificuldade de adaptação a nova territorialidade. Não são poucos os relatos de discriminação e xenofobia, recorrentes inclusive nos textos midiatizados.

\begin{abstract}
Desde julho, a Casa Latino Americana (Casla), organização que acolhe migrantes na capital paranaense, recebeu 13 haitianos que foram espancados por causa do preconceito. [...] os relatos detalham atitudes que escancaram a discriminação e que terminaram com agressões físicas graves. As vítimas estão recebendo assessoria jurídica da Casla, com apoio da Ordem dos Advogados do Brasil (OAB), por meio da Comissão de Direitos dos Migrantes. (GAZETA DO POVO $\left.{ }^{3}, 2015\right)$
\end{abstract}

Como bem lembra Curado:

\begin{abstract}
A discriminação e a xenofobia contra trabalhadores migrantes, por exemplo, além de derivar de motivos como a nacionalidade, a cor, a etnia, sexo e a religião, decorrem geralmente da idéia preconcebida que esses trabalhadores são uma ameaça ao equilíbrio da oferta e da demanda de empregos no mercado nacional de trabalho ou, em outras palavras, de que estes retiram dos nacionais as oportunidades de empregos, inclusive em razão de aceitarem receber salários mais baixos pela realização da mesma tarefa. (2011, p. 120)
\end{abstract}

Este estigma, que é produzido socialmente no migrante, gera nele uma sensação de estranhamento e de deslocamento, a partir do físico, do geográfico e do simbólico. Criam-se múltiplas fronteiras dificilmente transponíveis. Em muitos casos o

\footnotetext{
${ }^{3}$ Fonte: http://www.gazetadopovo.com.br/vida-e-cidadania/xenofobia-se-converte-em-agressoes-contraimigrantes-haitianos-ef4atki1925lz2d0e34rtiudq <acesso 18.03.2016>
} 
migrante nunca consegue se adaptar a nova realidade territorial seja no aspecto social, cultural ou econômico.

Canclini em Culturas hibridas, poderes oblíquos problematiza estes fluxos migratórios, repensando, sobretudo, as fronteiras culturais.

\begin{abstract}
Os estudos sobre o imperialismo econômico e cultural serviram para conhecer alguns dispositivos usados pelos centros internacionais de produção científica, artística e comunicacional que condicionavam, e ainda condicionam, nosso desenvolvimento. Mas esse modelo é insuficiente para entender as atuais relações de poder. Não explica o funcionamento planetário de um sistema industrial, tecnológico, financeiro e cultural, cuja sede não está em uma só nação, mas em uma densa rede de estruturas econômicas e ideológicas. Também não dá conta da necessidade das nações metropolitanas de flexibilizar suas fronteiras e integrar suas economias, sistemas educativos, tecnológicos e culturais, como está acontecendo na Europa e na América do Norte. (CANCLINI, 2013, p. 310)
\end{abstract}

Como assevera Canclini (2013), ao lembrar Michel de Certeau,"a vida consiste em passar constantemente fronteiras" (2013, p. 314).

Estas fronteiras também são desveladas a partir de outras referências. As fontes literárias e visuais mais variadas, tais como: biografias, etnografias, romances, filmes, documentários e obras de arte, têm problematizado estas transposições de fronteiras, sejam elas geográficas ou simbólicas muitas vezes metaforizadas.

\footnotetext{
Desterritorialização e reterritorialização. Nos intercâmbios da simbologia tradicional com os circuitos internacionais de comunicação, com as indústrias culturais e as migrações, não desaparecem as perguntas pela identidade e pelo nacional, pela defesa da soberania, pela desigual apropriação do saber e da arte. (CANCLINI, 2013, p.326)
}

Para Guatarri (1996, p.55), "Novas práticas sociais, novas práticas estéticas, novas práticas de si na relação com o outro, com o estrangeiro, com o estranho" auxiliam a compreender o mundo através de outra concepção estética.

Ações artísticas de Francis Alÿs

O artista conceitual Francis Alÿs, nascido em Amberes, Bélgica (1959), formou-se em arquitetura e em 1987, a serviço de ajuda militar, se deslocou ao México. Desde então, parte para o campo das artes visuais e, logo, pleiteia cidadania mexicana. Talvez este cruzamento de fronteiras, realizado por Alÿs (2015), possa identificar um 
bom ponto de partida para compreender a sua potente relação com os fluxos migratórios, presentes em inúmeros trabalhos de sua autoria.

Alÿs traz uma sensibilidade poética e imaginativa distinta para observações de tramas e acoplamentos com a vida cotidiana e situações políticas vivenciadas por pessoas migrantes. Ele se refere a estes temas como se percebesse individual e coletivamente as angústias dos migrantes ao transpor fronteiras.

$\mathrm{Na}$ vasta gama de projetos, ações e intervenções realizadas por Francis Alÿs (2015), encontram-se as projeções destas viagens, rotas de fuga e espaços fronteiriços demarcados. Entre Estados Unidos - México e Estados Unidos - Cuba, na fronteira entre Israel e a Palestina e no mar que separa Espanha e Marrocos, produzem-se obras visuais de um conteúdo estético e político marcante.

Elegeu-se para este artigo The Loop (1997), Green Line (2005), Bridge/Puente (2006) e Don't cross the bridge before you get to the river (2008), quatro (04) referências de Alÿs para compreender os campos dos fluxos migratórios e das fronteiras. Estas obras constituem-se em iconografias visuais capazes de prospectar uma iconologia (PANOFSKY, 1986) dos estudos culturais sobre os temas objetos deste estudo.

\footnotetext{
Assim, concebo a iconologia como uma iconografia que se torna interpretativa e, desse modo, converte-se em parte integral do estudo da arte, em vez de ficar limitada ao papel de exame estatístico preliminar. [...] Iconologia, portanto, é um método de interpretação que advém da síntese mais que da análise. E assim como a exata identificação dos motivos é o requisito básico de uma correta análise iconográfica, também a exata análise das imagens, estórias e alegorias é o requisito essencial para uma correta interpretação iconológica - a não ser que lidemos com obras de arte nas quais todo o campo do tema secundário ou convencional tenha sido eliminado e haja uma transição direta dos motivos para o conteúdo, como é o caso da pintura paisagística européia, da natureza morta e da pintura de gênero, sem falarmos da arte "não-objetiva". (PANOFSKY, 1986, p. 49)
}

A análise iconográfica trata de imagens, estórias e representações ao invés de motivos, desta forma, ela pressupõe muito mais que a familiaridade com objetos e fatos que se adquirem a partir de uma experiência vivida (PANOFSKY, 1986), por outro lado a análise iconológica necessita escavar quais os símbolos percorreram o autor da imagem. 
The Loop (1997)

Em 1997, Alÿs contorna de avião a fronteira entre os Estados Unidos da América e o México. Desde muito tempo contestada, a área fronteiriça que liga Tijuana (México) aos Estados Unidos, foi sempre uma das principais portas de entrada de migrantes mexicanos na América do Norte, tendo San Diego (Califórnia) como primeiro destino.

Utilizando-se do valor recebido para uma exposição que realizou em San Diego, Alÿs viajou de avião a partir de Tijuana para a Cidade do México, logo, percorreu: Cidade do Panamá, Santiago, Auckland, Sydney, Cingapura, Bangkok, Rangoon, Hong Kong, Xangai, Seul, Anchorage, Vancouver, Los Angeles, e, finalmente, rumou ao sul dos Estados Unidos chegando em San Diego, Califórnia.

Esta intervenção/ação de caráter aparentemente extravagante demonstra, ao mesmo tempo, as dificuldades enfrentadas pelos cidadãos mexicanos ao tentar cruzar a fronteira dos EUA, bem como os excessos de viagens que percorrem cotidianamente o mundo da arte na década de 1990. O que Alÿs expõe, é uma suposta falha no controle de fronteira entre México e Estados Unidos, apresentando-o através de um circuito físico em uma escala global, Contudo, ao fazê-lo destaca o fato de que isso só poderia ser possível para uns poucos privilegiados. 


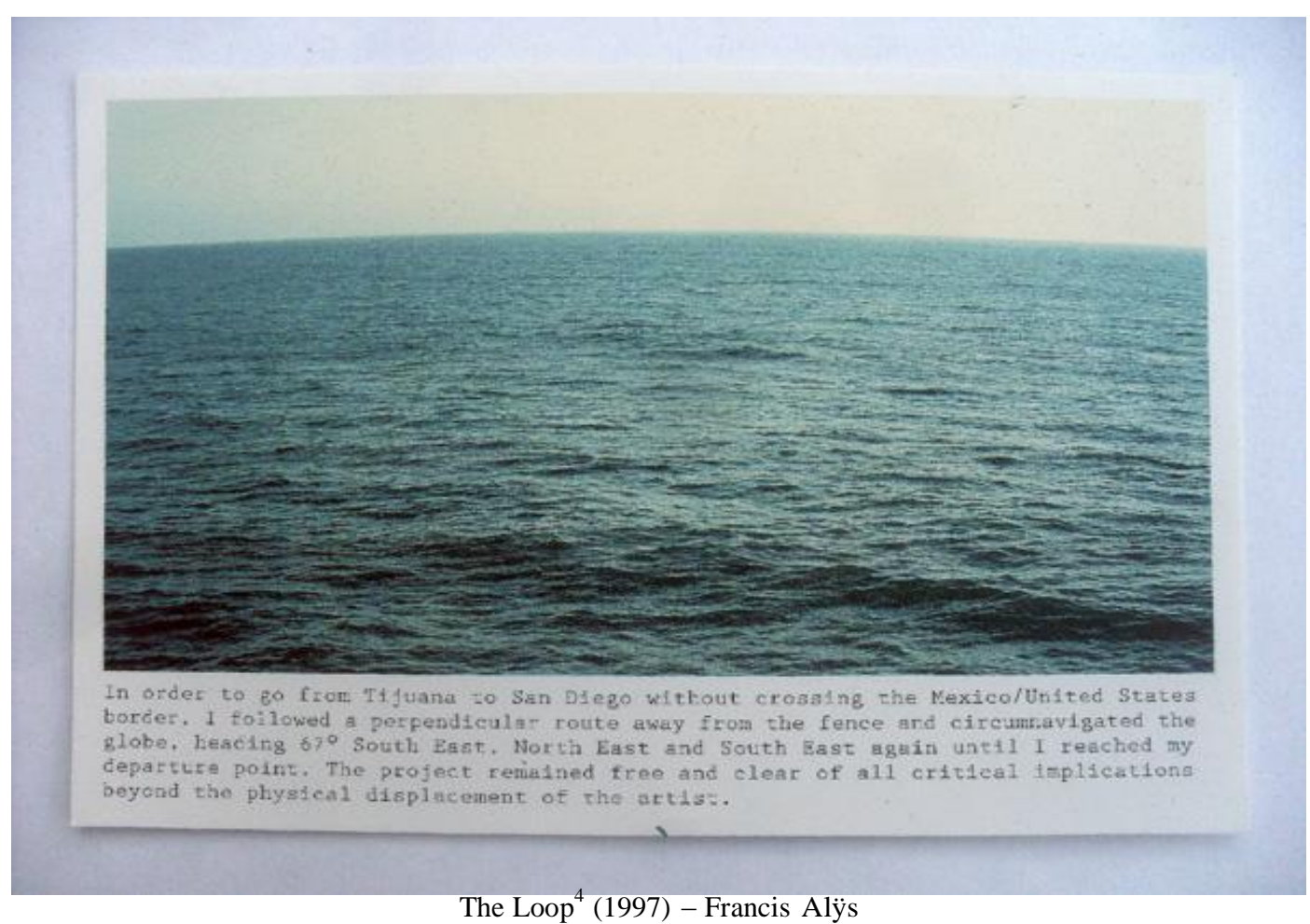

In order to go from Tijuana to San Diego without crossing the Mexico/United States border, I followed a perpendicular route away from the fence and circumnavigated the glove, heading 67 degrees South East, North East and South East again until I reached my departure point. The project remained free and clear of all critical implications beyond the physical displacement of the artist. (ALŶS, 1997)

Neste aspecto, "The Loop" (1997), de Alÿs, abre a possibilidade interpretativa da arte. The Loop pode nos conectar as novas formas de ver o cotidiano e pode expandir novos modos de investigação qualitativa e visual, já que detêm o potencial para debater as políticas públicas de migração e os limites do significado são expandidos para incluir diferentes formas de abordar as questões da imigração.

\footnotetext{
${ }^{4}$ Fonte: http://pietmondriaan.com/2012/11/11/francis-alys-4/ <acesso 15.03.2016>

${ }^{5}$ Em tradução livre: "A fim de ir de Tijuana à San Diego, sem atravessar a fronteira México / Estados Unidos, eu segui uma rota perpendicular longe da cerca e circundei o mundo, dirigindo-me 67 graus Sudeste, Nordeste e Sudeste novamente, até chegar ao meu ponto de partida . O projeto permanece livre e desembaraçado para quaisquer implicações críticas sobre o deslocamento físico do artista."
} 


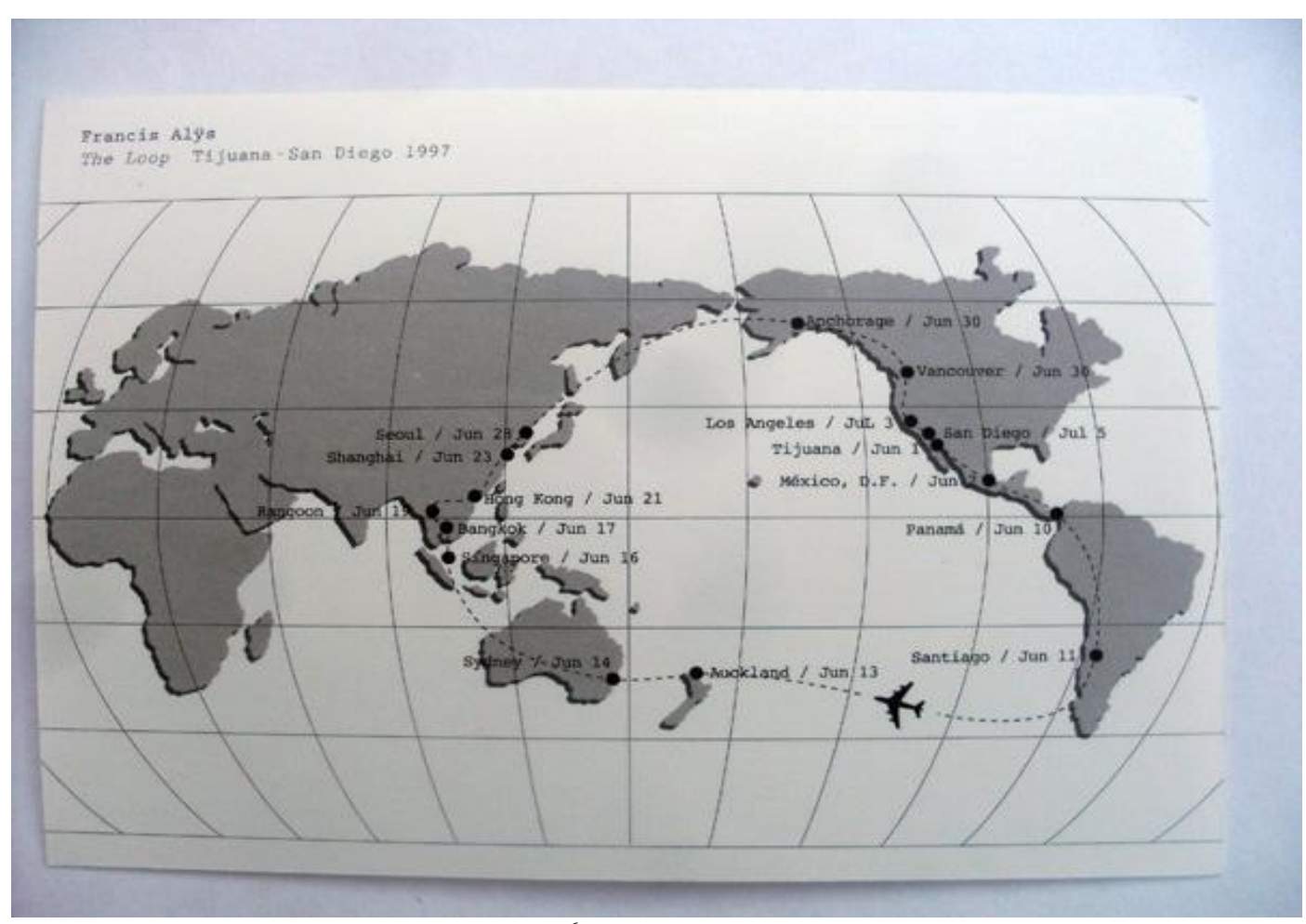

The Loop ${ }^{6}$ (1997) - Francis Alÿs

Green Line (2005)

No verão de 1995, Alÿs realiza uma caminhada na cidade de São Paulo, a ideia era, com um vazamento em uma lata de tinta azul, produzir uma ação, lido à época como um gesto poético. Em Green Line (2005), o artista questiona abertamente o papel e a relevância da poética em situação de conflito político, tendo em conta a mesma perspectiva da intervenção de 1995.

Green Line (2005) é uma ação que ocorre em Jerusalém, e que, portanto, se passa no cruzar da fronteira entre Israel e a Palestina. Tomando como elemento a ação realizada em São Paulo, Francis Alÿs, percorre a pé cerca de vinte e cinco (24) kilometros. Cinquenta e oito (58) litros de tinta verde foram usados para rastrear estes $24 \mathrm{~km}$. Ao mesmo tempo, com auxílio de outros profissionais, realiza-se um documentário filmando a caminhada, sendo este apresentada a um número de pessoas, que eram convidadas a se manifestar sobre a ação e as circunstâncias em que foi realizada.

\footnotetext{
${ }^{6}$ Fonte: http://pietmondriaan.com/2012/11/11/francis-alys-4/ <acesso 15.03.2016>
} 


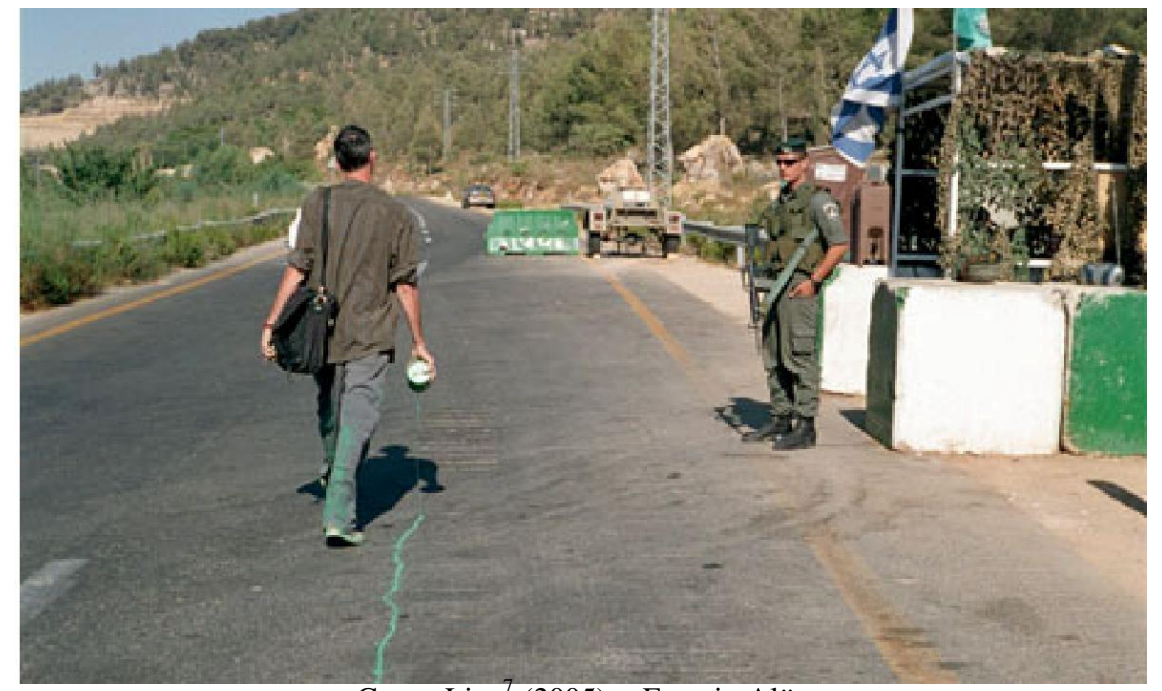

Green Line 7 (2005) - Francis Alÿs

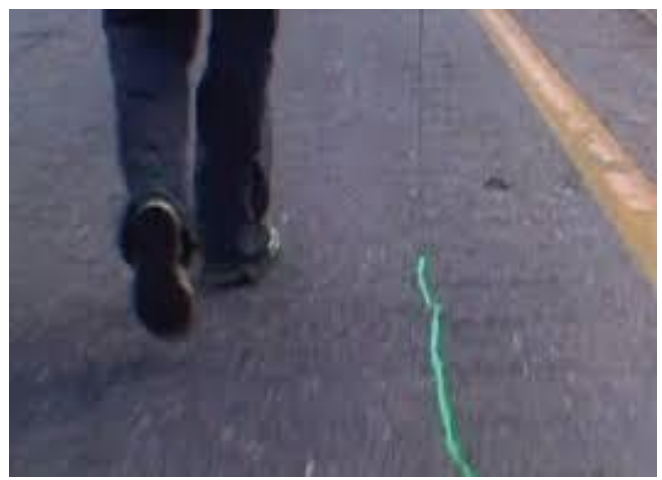

Green Line (2005) - Francis Alÿs

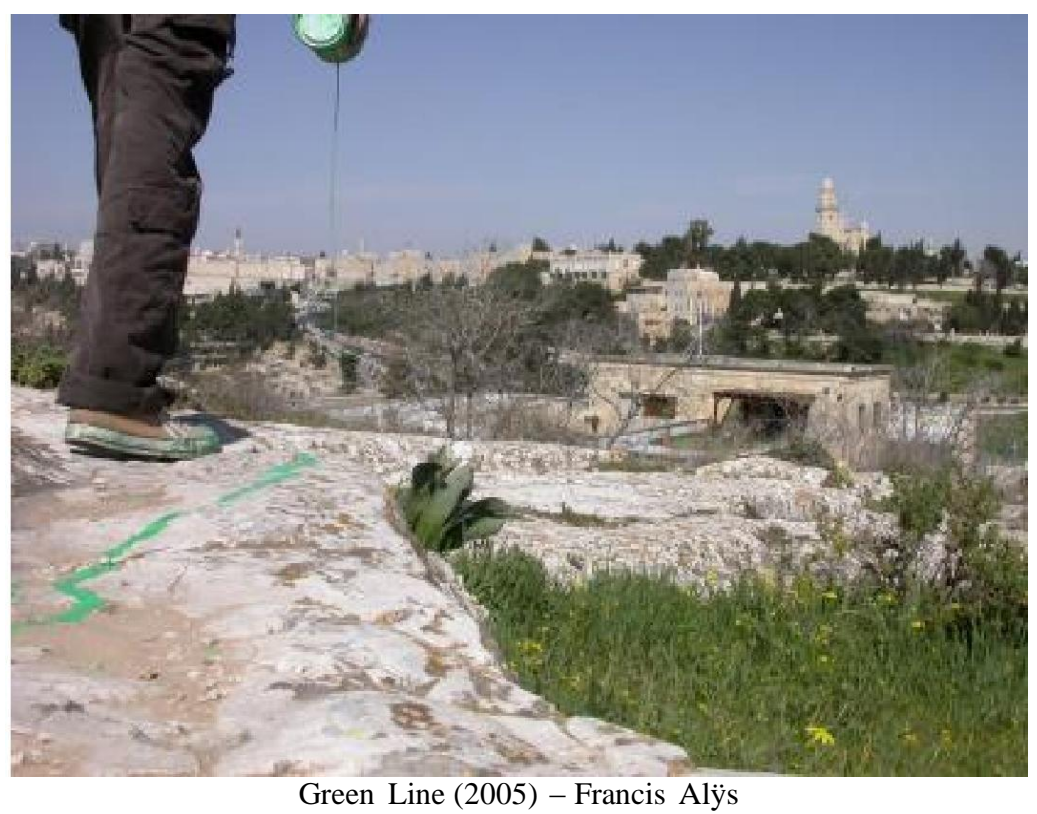

$\overline{{ }^{7} \text { Fonte: http://francisalys.com/the-green-line/ }}$ < acesso em 15.03.2016> 
Alÿs anda do sul ao norte da cidade de Jerusalém. Percorre a fronteira internacionalmente reconhecida que separam judeus e palestinos e, procura, através de uma linha verde, demonstrar a terrível separação que se produz invisivelmente. Caminhando por dois dias, o artista derrama a tinta descuidadamente. Ele passa pelos soldados que nada vêem, circunda na frente de crianças brincando e rindo, cruza na frente de adultos que não entendem a sua ação.

Em toda fronteira há arames rígidos e arames caídos. As ações exemplares, os subterfúgios culturais, os ritos são maneiras de transpor os limites por onde é possível. (CANCLINI, 2013, p. 349)

Esta intervenção artística de Francis Alÿs questiona-nos sobre o papel político da arte, e sobremaneira, de uma arte engajada que questiona elementos como o direito de cidadania, a migração e as fronteiras.

\begin{abstract}
As práticas culturais são, mais que ações, atuações. Representam, simulam as ações sociais, mas só às vezes operam como uma ação. Isso acontece não apenas nas atividades culturais expressamente organizadas e reconhecidas como tais; também os comportamentos ordinários, agrupados ou não em instituições, empregam a ação simulada, a atuação simbólica. Os discursos presidenciais ante um conflito insolúvel com os recursos que se têm, a crítica à atuação governamental de organizações políticas sem poder para revertê-la e, é claro, as rebeliões verbais do cidadão comum são atuações mais compreensíveis para o olhar teatral que para o do político "puro". A antropologia nos informa que isso não se deve à distância que as crises colocam entre os ideais e os atos, mas à estrutura constitutiva da articulação entre o político e o cultural em qualquer sociedade. Talvez o maior interesse para a política de levar em conta a problemática simbólica não resida na eficácia pontual de certos bens ou mensagens, mas no fato de que os aspectos teatrais e rituais do social tornem a evidente o que há de oblíquo, simulado e distinto em qualquer interação. (CANCLINI, 2013, p. 350)
\end{abstract}

Bridge/Puente (2006)

A questão da constituição simbólica do espaço e, portanto, suas implicações, limitações e fronteiras tem sido uma constante na investigação de Alÿs (2015). Sua maneira de criar e de explorar ideias, sobretudo, o questionamento das margens dos próprios conceitos, como o território, fronteira, representação, evento e o binômio política e poética. Seu trabalho marca a solidez conceitual de um artista cosmopolita e híbrido (CANCLINI, 2013), que consegue unir sem ignorar a especificidade de cada um.

Pequenos atos sobre a borda do espaço público e do privado, que seriam imperceptíveis na vida cotidiana, são os significantes artísticos da política na obra de 
Alÿs (2015). Em Bridge/Puente ${ }^{8}$, ação realizada em Havana, Cuba e Key West, Florida, em 2006, estes elementos políticos estão presentes.

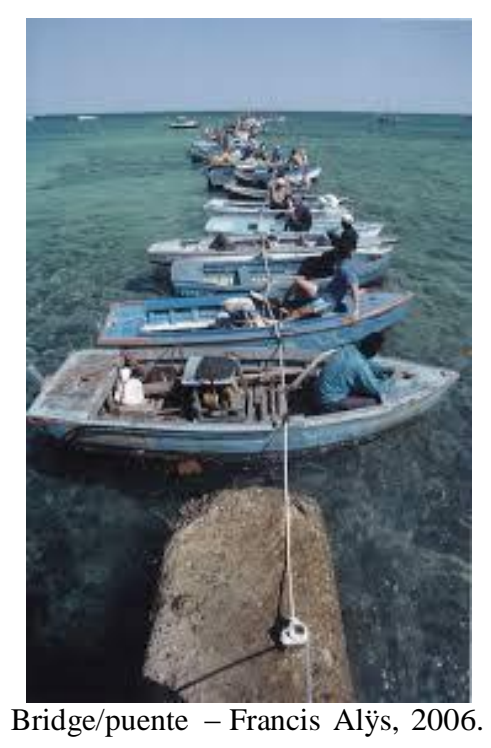

Nesta obra, Alÿs tenta criar a ilusão de uma ponte flutuante entre a Flórida e Havana com uma corrente de barcos de pesca alinhados a partir de ambas as costas, sob a forma de uma linha, de modo que eles tentem se ligar em algum lugar no horizonte. A imagem faz referência a um diálogo fictício entre dois países que possuem barreiras físicas e diplomáticas.

\footnotetext{
$\overline{{ }^{8} \text { http://francisalys.com/bridge-puente/ }}$
} 


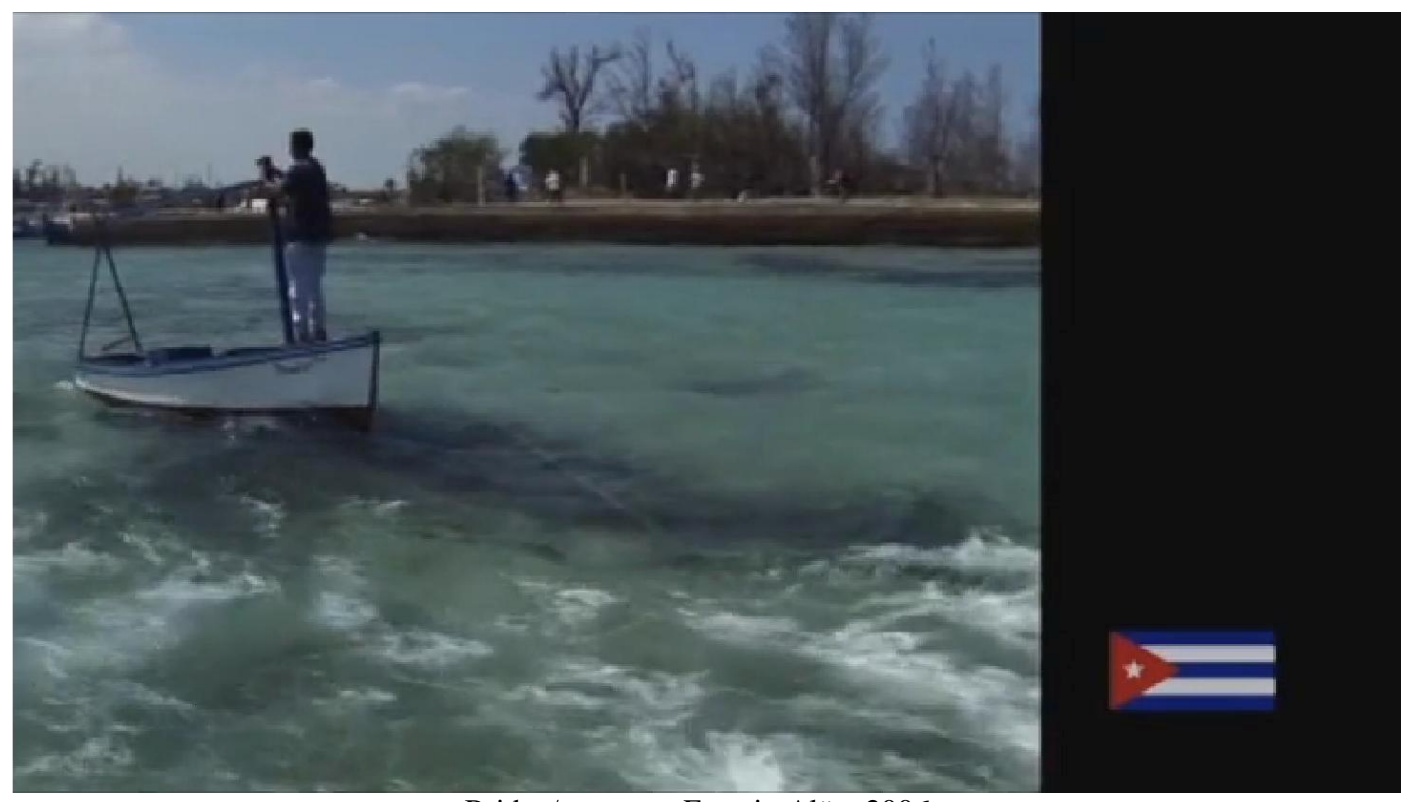

Bridge/puente - Francis Alÿs, 2006.

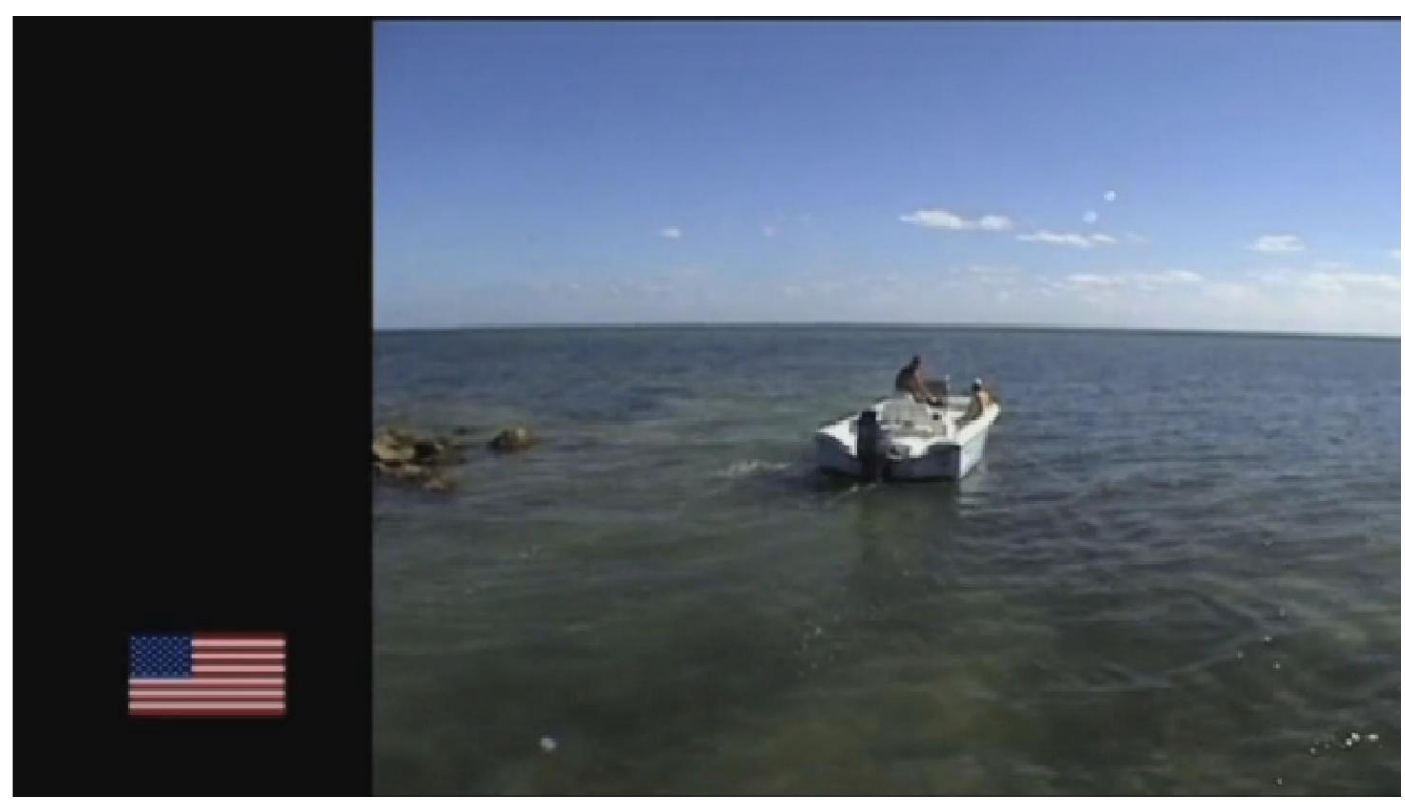

Bridge/puente - Francis Alÿs, 2006.

O que Alÿs nos apresenta em Bridge/Puente (2006) é uma intervenção ação motivada por contradições geopolíticas, colocadas pela economia global a partir do fenômeno dos fluxos migratórios, políticas protecionistas e representação social e 
cultural, que povoam as relações entre países na dicotomia norte-sul ${ }^{9}$ (SANTOS; MENESES, 2010).

\begin{abstract}
Essas práticas de arte pública desmaterializada e efêmera, categoria na qual se encaixa Bridge / Puente, têm sido associadas às questões da vida pública cotidiana por propiciarem uma dilatação do escopo dos "tipos de questões que elegem para discutir, e não por sua acessibilidade e pelo volume de espectadores", enredando-se em um processo de contaminação crescente com questões políticas do cotidiano. Nessas práticas, a cultura se inscreve no fazer da vida diária, em processos que se (i)materializam fora dos museus, das salas de concerto e dos grandes teatros de ópera. Um processo de cultura que não precisa ser criado em ateliês, pois em permanente construção, para sempre inconcluso, para sempre inacabável. (OLIVEIRA, 2014, p. 06-07)
\end{abstract}

Don't cross the bridge before you get to the river ${ }^{10}$ (2008)

Estreito de Gibraltar, Marrocos, Espanha, em colaboração com Rafael Ortega, Julien Devaux, Felix Blume, Ivan Boccara, Abbas Benhim, a Fundación Montenmedio de Arte e um grupo de crianças de Tanger (Marrocos) e Tarifa (Espanha), Alÿs (2015) desenvolve o que seria o segundo episódio ${ }^{11}$ de um importante debate sobre o fluxo migratório.

Em Don't cross the bridge before you get to the river (2008) o artista volta seus olhares para o Norte da África e Sul da Europa, mais precisamente o Mar Mediterrâneo. Tal qual em Bridge/Puente (2006), Alÿs diagnostica um limite geográfico marcado por uma fronteira intransponível, na qual milhares de migrantes perdem suas vidas tentando atravessar.

Era 12 de agosto de 2008, quando uma linha de crianças transportando em suas mãos um barco feito de sapato deixa a Europa (simbolicamente) em direção ao Marrocos (Tanger). No mesmo instante, uma segunda linha de crianças com sapatos que se transformam artisticamente em barcos deixa o Norte da África em direção à Espanha, (Tarifa). As duas linhas pretendem se reunir no horizonte.

\footnotetext{
${ }^{9}$ Em Epistemologias do Sul (SANTOS; MENESES, 2010) é referenciada a metáfora que trata de reparar os impactos historicamente causados pelo capitalismo na sua relação colonial com o mundo. Aqui a referência é a exploração do sul global pelo norte. Embora, as relações de opressão ocorram em ambos espaços geográficos, é a partir de/ e para o norte que se apontam as relações marcadamente coloniais.

${ }_{10} \mathrm{http}$ ://francisalys.com/dont-cross-the-bridge-before-you-get-to-the-river/ <acesso 18.03.2016>

11 O termo episódio é utilizado por Alÿs (2015) ao se referir a Bridge em duas etapas: Bridge/Puente (2006) e Don't cross the bridge before you get to the river (2008).
} 
O projeto denominado Gibraltar refletia duas imersões: uma poético-estética, utilizando uma brincadeira de criança com o mar e o desejo de navegar e outra política, questionando as fronteiras entre estes dois continentes (ALYS, 2015).

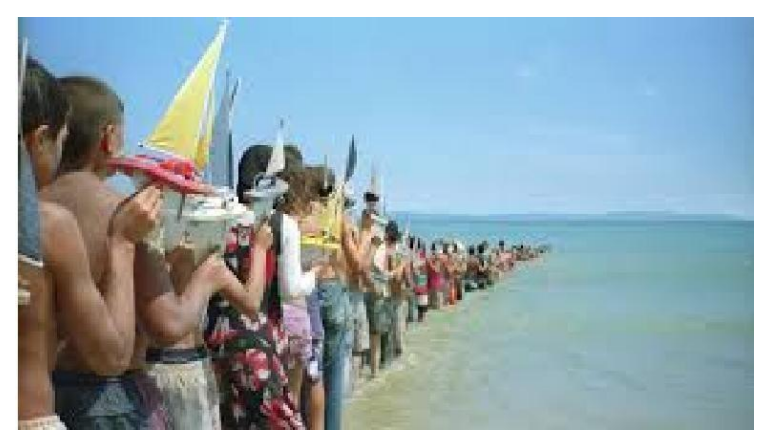

Don't cross the bridge before you get to the river (2008) - Francis Alÿs, 2008.

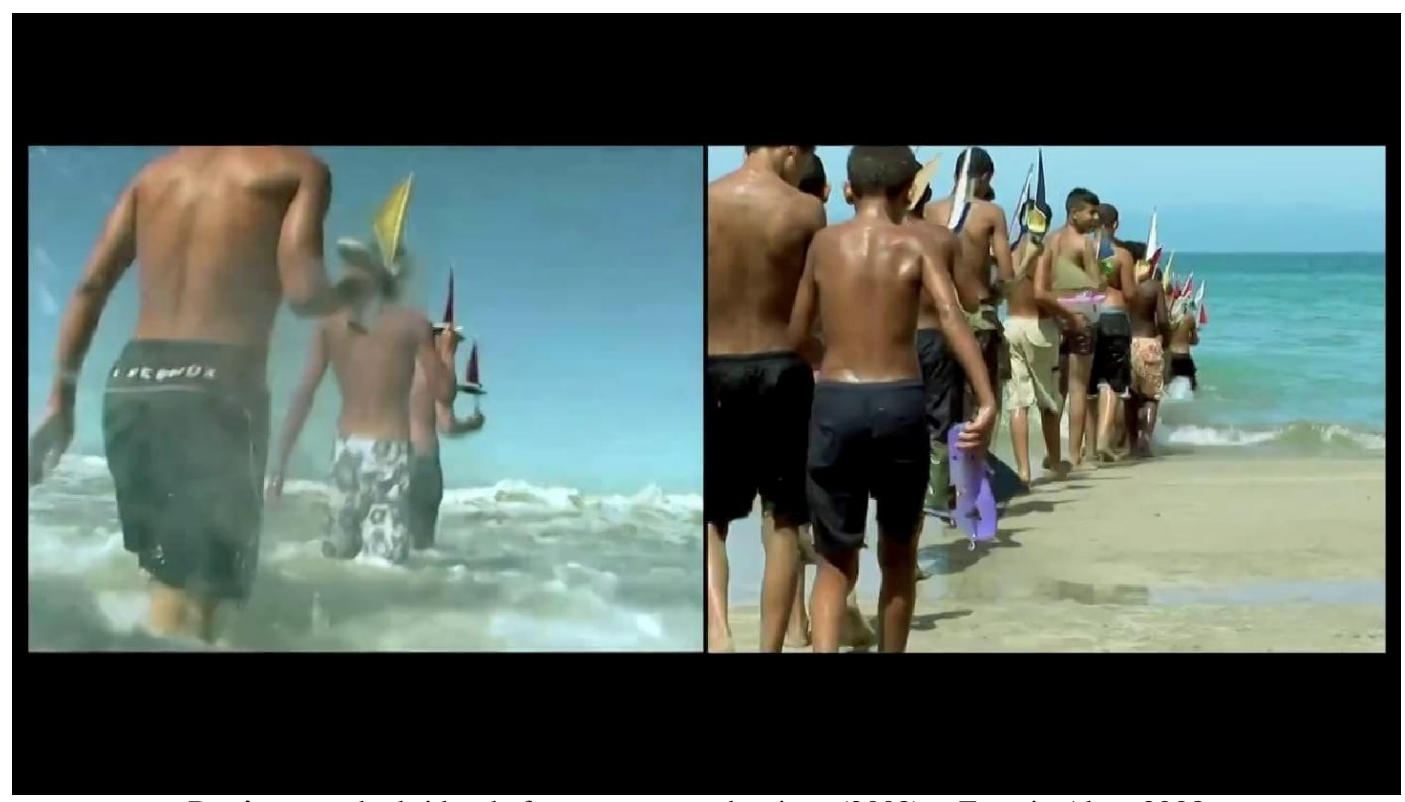

Don't cross the bridge before you get to the river (2008) - Francis Alÿs, 2008. 


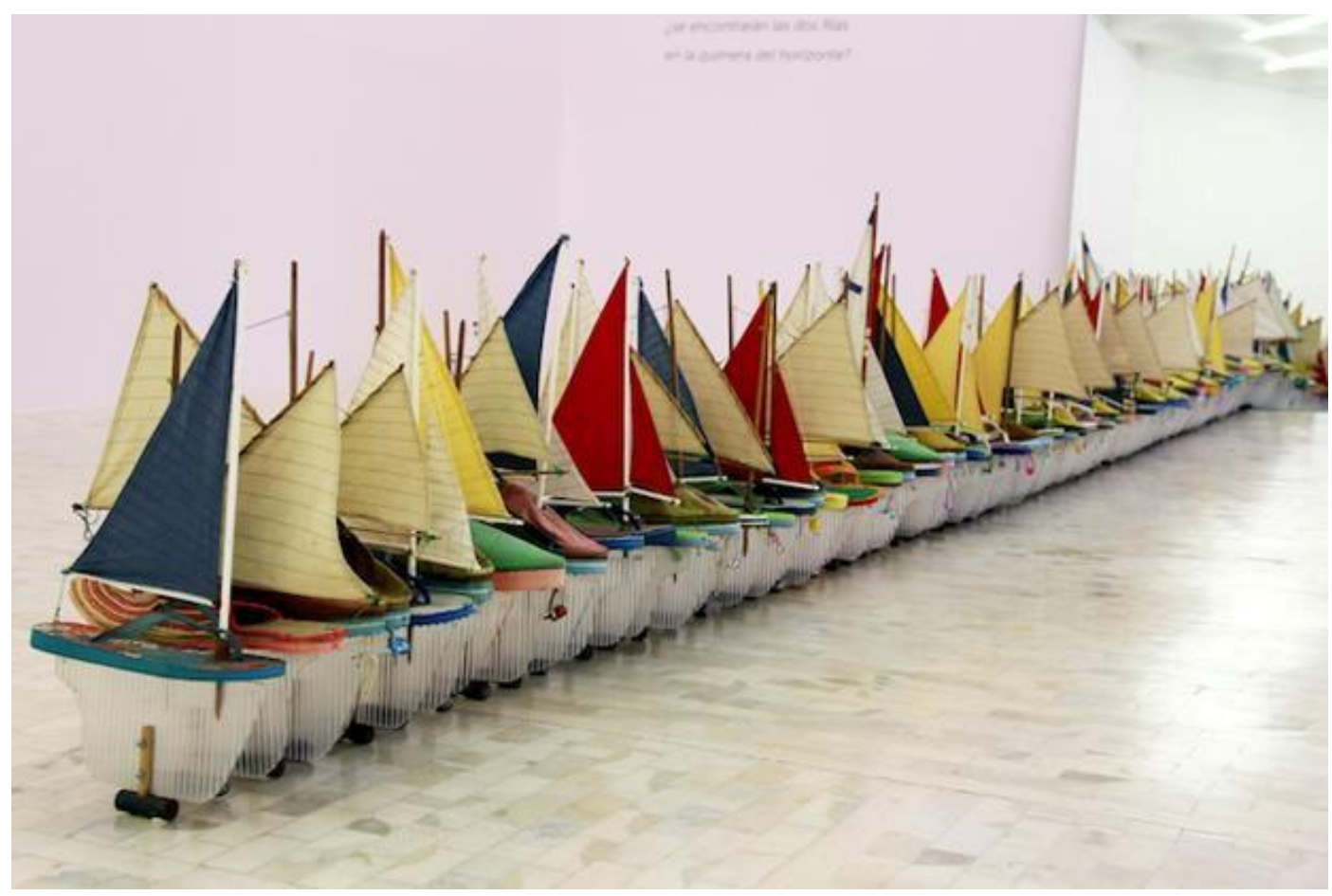

Don't cross the bridge before you get to the river (2008) - Francis Alÿs, 2008.

Alÿs, sutilmente, minimiza o componente geopolítico e destaca a dimensão poética, mirando sua ação nas crianças. No espaço expositivo, o vídeo de sete (07) minutos produzido por Alÿs é apresentado em duas telas, dando a noção exata e instantânea da ação proposta. No vídeo, o Estreito de Gibraltar com quatorze quilômetros $(14 \mathrm{~km})$ denota a separação, física e simbólica, entre a África e a Europa.

As crianças entrando no Mediterrâneo transportando um brinquedo, um barco feito com sandálias (restos de sapatos), o dia ensolarado e a água permitem problematizar os sonhos, as tramas e as contradições de nossos tempos. "Como pode alguém fomentar a economia global e, ao mesmo tempo, limitar o fluxo global de pessoas entre os continentes?” nos interroga Alÿs (2015, p. 113). 


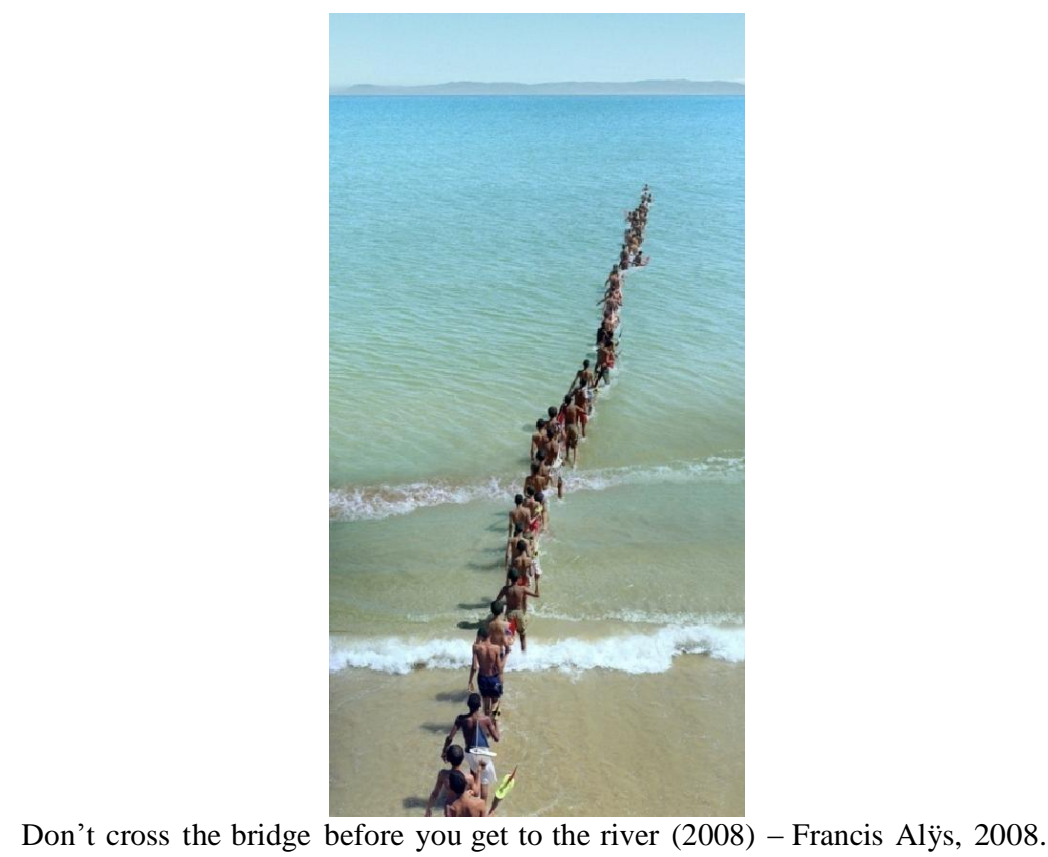

Considerações finais

As obras de Francis Alÿs, The Loop (1997), Green Line (2005), Bridge/Puente (2006) e Don't cross the bridge before you get to the river (2008), são importantes referências para compreender os fluxos migratórios e as fronteiras espalhados ao redor do mundo globalizado.

O papel epistemológico, tanto como de retórica visual, de Alÿs (2015) nunca é fixo. De fato, em seus projetos, ações, intervenções e pinturas aparecem de maneira evidente o diálogo poético-político do artista, sem necessariamente determinar um único sentido/significado. Esta iconologia forma um diagrama praticamente estrutural, tão sistemático quanto engajado, pois apresenta a vida cotidiana entre o poético, o ético, o estético e a política.

As intervenções do artista Francis Alÿs questionam as (im)potências expressas nas ações fadadas a incompletude. Em Bridge/Puente (2006) e Don't cross the bridge before you get to the river (2008), estas (im)potências apresentam-se mais visíveis, denunciando a difícil trajetória de quem busca cruzar a fronteira.

Para Alÿs (2015, p. 213), "o Estreito de Gibraltar parecia o lugar óbvio para ilustrar esta contradição do nosso tempo" dialogar uma ponte imaginária entre os 
continentes europeu e africano. Com uma distância de apenas $14 \mathrm{~km}$ entre os continentes, o estreito demonstra ser um lugar perigoso para os imigrantes ilegais que tentam fazer o seu caminho para um novo continente e uma nova vida.

A imagem desperta tanto interesse porque ela nem sempre produz um único significado, um único sentido. Ela indica infinitas possibilidades. Esta produção de sentidos pode ser um elemento dificultador na análise e nos usos da imagem, mas. por outro ângulo, essa multiplicidade torna-se um potente desafio epistemológico.

"La langue de l'image, ce n'est pas seulement l'ensemble des paroles émises (par exemple au niveau du combinateur des signes ou créateur du message), c'est aussi l'ensemble des paroles reçues: la langue doit inclure les «surprises » du sens. ${ }^{\text {12 }}$ (BARTHES, 1964, p. 48).

Esta investigação, embora tenha tido como objeto de análise algumas das obras de Alÿs, procurou demonstrar o quão importante são os métodos qualitativos que aliam texto e imagem. Inspirado nesta pesquisa, como já referido anteriormente, propôs-se problematizar os fluxos migratórios e os enredados espaços fronteiriços em que cruzam (ou tentam cruzar) migrantes de todas as partes do mundo.

Entende-se que em um mundo globalizado, mesmo permeado pelo capitalismo, deve sobre pairar os princípios da cidadania global e da não violação dos direitos humanos. Neste sentido, urge defender intransigentemente o direito de liberdade, incluído as prerrogativas de livre acesso a pessoa migrante, favorecendo os fluxos e os deslocamentos fronteiriços. O campo das artes visuais pode potencializar este debate.

Acredita-se fundamental utilizar o fazer artístico como elemento problematizador para a política e o direito. Defende-se que investigações que dialoguem os estudos e a cultura visual, o direito e a política podem auxiliar a compreender o mundo global sobre outras perspectivas.

\footnotetext{
12 Em tradução livre; "A linguagem da imagem (imagética) não é somente o somatório das palavras emitidas (por exemplo, em nível de combinar os signos ou criar uma mensagem), ela é, também, o conjunto de palavras recebidas: a língua deve incluir as 'surpresas' de sentido."
} 
Referências

ALYS, Francis. Relato de uma negociación. Una investigación sobre lãs acatividades paralelas del performance y la pintura. México D. F.: Instituto Nacional de Bellas Artes y Literatura, 2015.

ARAÚJO, Natália Medina. Migrantes indocumentados: histórias e aporias. In: GALINDO, George Rodrigo Bandeira (Organizador). Migrações, deslocamentos e direitos humanos. 1. ed. - Brasília: IBDC; Grupo de Pesquisa C\&DI, 2015. p. 26-35.

BARTHES, Roland. Réthorique de l'image. Communications, no 4, 40-51, 1964.

BOHNSACK, Ralf. A interpretação de imagens e o método documentário. Sociologias, Porto Alegre, ano 9, nº 18, p. 286-311, jun./dez. 2007.

BOURRIAUD, Nicolas. Estética relacional. São Paulo: Martins, 2009.

CANCLINI, Néstor Garcia. Culturas híbridas. Estratégias para entrar e sair da modernidade. São Paulo: Edusp, 2013.

CURADO. Flaviane Silveira. Desafios e perspectivas para a efetivação dos direitos humanos dos trabalhadores migrantes em tempos de globalização. In: FILHO, Robério Nunes dos Anjos (Organizador). Globalização, justiça e segurança humana: capacitação para a compreensão dos grandes desafios do século XXI. Brasília: ESPMU, 2011. p. 99-125.

DIAS, Renato Duro. Séries de animação: diálogos entre direito, arte e cultura popular. In: CONPEDI/UFS. (Org.). 1 ed. Florianópolis: CONPEDI, 2015a, v. 1, p. 394-410.

. Interdição de gênero: a lei que silencia o corpo. In: CONPEDI/UFMG/FUMEC/ Dom Helder Câmara. (Org.). Direito, arte e literatura. 1ed. Florianópolis: CONPEDI, 2015b, v. 1, p. 467-484.

Acesso à justiça e educação jurídica: uma percepção imagética do direito. In: CONPEDI/UFSC. (Org.). Direito, Educação, Ensino e Metodologias Jurídicos. 1ed. Florianópolis: CONPEDI 2014, 2014, v. 01, p. 29-43.

GUATARRI, Félix. As três ecologias. Madrid: Pretextos, 1996.

KANT, Immanuel. Para a paz perpétua. PIM, Joám Evans. Estudo Introdutório. Trad. Bárbara Kristensen. Rianxo: Instituto Galego de Estudos de Segurança Internacional e da Paz, 2006. Disponível em: http://ir.nmu.org.ua/bitstream/handle/123456789/130522/3bff59227cc7c6d6f40d377a4d 182b58.pdf?sequence=1. <Acesso em: 08/03/2016>

KERBER, Eduardo da Costa. A superação do estatuto do estrangeiro sob a ótica dos direitos humanos: discutindo a legislação brasileira sobre migrações. Rio Grande: FURG, 2015.

KOSER, Khalid. International Migration. A very short introduction. New York, USA: Oxford University Press, 2007. 
MARINUCCI, Roberto e MILESI, Rosita. Migrações internacionais contemporâneas. $\quad$ http://www.migrante.org.br/index.php/refugiados-as2/143migracoes-internacionais-contemporaneas < acesso. 11.03.2016.

OLIVEIRA, Luiz sérigio de. Utopias do contemporâneo: legados do modernismo nas práticas de arte pública. Revista Caiana, v.4, primer semestre, 2014. http://caiana.caia.org.ar/template/caiana.php?pag=articles/article_1.php\&obj=135\&vol= $\underline{4}$ <acesso 18.03.2016>

PANOFSKY, Erwin. Iconografia e iconologia: uma introdução ao estudo da arte da renascença. In: Significado nas Artes Visuais. Tradução: Maria Clara F. Kneese e J. Guinsburg. São Paulo: Perspectiva, 2a ed., 1986, p. 47-65.

PANOFSKY, Erwin. Significado nas artes visuais. São Paulo: Perspectiva, 2011.

SANTOS, Boaventura de Sousa; MENESES, Maria Paula. Epistemologias do Sul. São Paulo: Cortez, 2010. 